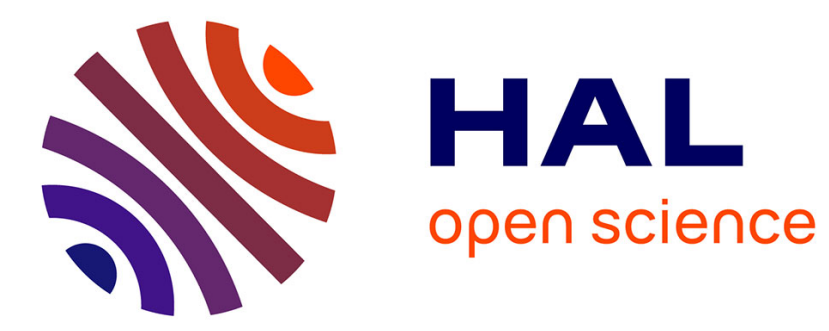

\title{
Measuring project complexity using the Analytic Hierarchy Process
}

Ludovic-Alexandre Vidal, Franck Marle, Jean-Claude Bocquet

\section{To cite this version:}

Ludovic-Alexandre Vidal, Franck Marle, Jean-Claude Bocquet. Measuring project complexity using the Analytic Hierarchy Process. International Journal of Project Management, 2011. hal-01215358

\section{HAL Id: hal-01215358 \\ https://hal.science/hal-01215358}

Submitted on 14 Oct 2015

HAL is a multi-disciplinary open access archive for the deposit and dissemination of scientific research documents, whether they are published or not. The documents may come from teaching and research institutions in France or abroad, or from public or private research centers.
L'archive ouverte pluridisciplinaire HAL, est destinée au dépôt et à la diffusion de documents scientifiques de niveau recherche, publiés ou non, émanant des établissements d'enseignement et de recherche français ou étrangers, des laboratoires publics ou privés. 


\title{
Measuring project complexity using the Analytic Hierarchy Process
}

\author{
VIDAL Ludovic-Alexandre ${ }^{1}$, MARLE Franck ${ }^{1}$, BOCQUET Jean-Claude ${ }^{1}$ \\ ${ }^{1}$ Laboratoire Genie Industriel, Ecole Centrale Paris, 92290 Châtenay-Malabry, France
}

\section{Abstract}

Project complexity is ever growing and needs to be understood and measured better to assist modern project management. The overall ambition of this paper is therefore to define a measure of project complexity in order to assist decision-making. A synthesised literature review on existing complexity measures is proposed in order to highlight their limitations. Then, we identify the multiple aspects of project complexity. We then propose a multi-criteria approach to project complexity evaluation, through the use of the Analytic Hierarchy Process. In the end, it permits to define a relative project complexity measure. Complexity scales and subscales are defined in order to highlight the most complex alternatives and their principal sources of complexity within the set of criteria and sub-criteria which exist in the hierarchical structure. Finally, a case study within a start-up firm in the entertainment industry is performed. Conclusions and research perspectives are given in the end.

\section{Keywords}

Project, Complexity, Evaluation, Multi-criteria, Analytic Hierarchy Process (AHP). 


\section{Introduction}

A project is a temporary and unique endeavour undertaken to deliver a result. This result is always a change in the organization, whatever it is in its processes, performance, products or services. This transformation consists then in a gap between a start and a final state. Time and resources are consumed to produce results, which may be deliverables and/or performance improvement and/or resource improvement (skills, knowledge). Each project is unique because there is always at least one of the following parameters that changes: targets, resources and environment. This makes making project management an even more complex process.

For all practical purposes, lots of studies have been done, based on statistical calculations or surveys. Limits and lacks have been detected in research as well as in industry about the project predictability. Namely, usual parameters (time, cost and quality) are clearly not sufficient to describe properly the complete situation at a given time. As a whole, the conclusion of these studies is that current methods have shown their limits, since they cannot face anymore the stakes of ever growing project complexity, which results in damages or failures for the projects (Williams, 1999), (Whitty and Maylor, 2009). In other words, project ever growing complexity is an ever growing source of project risks. Identifying existing project complexity sources and levels of project complexity has thus become a crucial issue in order to assist modern project management. The main objective is then to build up a project complexity index so it can be used as an indicator, notably when facing the issue of project selection in multi-project environments.

\section{Measuring project complexity: a literature review}

\subsection{Project complexity definition}

Research works on the concept of complexity have been conducted for years. The difficulty is that there is actually a lack of consensus on what project complexity really is. As Sinha et al. (Sinha et al., 2001) underline it, "there is no single concept of complexity that can adequately capture our intuitive notion of what the word ought to mean". Complexity can be understood in different ways, not only in different fields, but has also different connotations within the same field (Morel \& Ramanujam, 1999). As for us, we propose the following definition for project complexity based 
on some additional works (Baccarini, 1999), (Edmonds, 1999), (Marle, 2001), (Austin et al., 2002), (Vidal et al., 2008): "project complexity is the property of a project which makes it difficult to understand, foresee and keep under control its overall behaviour, even when given reasonably complete information about the project system."

\subsection{Existing project complexity measures}

As far as this research work is concerned, a literature review on existing (project) complexity measures was performed. A total of 42 measures were listed, notably thanks to the works of Edmonds (Edmonds, 1999), Latva-Koivisto (Latva-Koivisto, 2001) or Nassar and Hegab (Nassar and Hegab, 2006). If interested, one should directly refer to them for more information on complexity measures and formulations. As a whole, there are basically three kinds of project complexity measures which can be found in the literature.

The first group gathers measures which correspond to the computational complexity of some project management issues, such as the sequencing and scheduling problem (Akileswaran, 1983). The second group gathers measures which are related to a model of the project structure as a graph (task graph, organisation graph, etc...). For instance, we can think of:

- The Coefficient of Network Complexity (CNC) defined by Kaimann (Kaimann, 1974) applies to both PERT and precedence networks. They can also apply to any model of a project as a graph. In the case of PERT networks, the CNC is equal to the quotient of activities squared divided by events.

- $\quad$ The cyclomatic number defined by Temperley (Temperley, 1981) is given in equation (1). S is the cyclomatic number, $\mathrm{A}$ is the number of arcs, $\mathrm{N}$ is the number of nodes.

$S=A-N+1$

- $\quad$ Arguing that complexity measures such as $\mathrm{CNC}$ are imperfect since they take redundant arcs into account and therefore show that the system is more complex than it actually is, Nassar and Hegab (2006) define the following measure:

$$
\begin{aligned}
& C n=100 \times\left(\log (a /(n-1)) / \log \left[\left(n^{2-1}\right) / 4(n-1)\right]\right) \% \text { if } n \text { is odd } \\
& C n=100 \times\left(\log (a /(n-1)) / \log \left[n^{2} / 4(n-1)\right]\right) \% \text { if } n \text { is even }
\end{aligned}
$$


The third group gathers more holistic measures such as systems thinking oriented measures or informational measures. For instance, we can think of:

- The traditional static entropic measurement of complexity by the Shannon information (Shannon, 1951)

$$
\text { Sha }=-\Sigma \log _{2}\left(p\left(n_{i}\right)\right)
$$

- Even though not calculated in the book, complexity indexes may be deduced from the areas of spider charts used by Haas (2009), who described project complexity using a complex systems thinking approach to identify several aspects of complexity (such as team composition and performance, cost/duration or political sensitivity/multiple stakeholders). This approach is particularly adapted to the issue of project selection.

\subsection{Limits of existing project complexity measures}

Existing measures have shown their limits for several reasons. First, some limits have been highlighted about the reliability of such measures. Second, these measures are often non intuitive for the final users and thus give results which are difficult to communicate on. Finally, these measures mainly refer to a model of the project system.

For the first group of computational complexity measure, the main drawback is that they do not focus on the complexity of the project system in itself. Indeed, with such measures, it can only be assessed given the bias of a specific issue like scheduling.

For the second group of graph-based complexity measures, some of them lack of reliability since counterexamples can be found. For instance, some graphs and networks were sharing the same CNC but were very different considering their easiness to be managed. One of the main reasons for this lack of reliability is that these measures refer to a single aspect of (project) complexity, essentially in terms of interdependencies. Moreover, measures such as the CNC, the cyclomatic number or the one proposed by Nassar and Hegab refer in essence to an existing network or graph. Such graphs are specific models of the project system, which restrict the view and understanding of project complexity. For instance, a project can be modelled thanks to different WBS (Work Breakdown Structure), PERT networks or Gantt charts, depending on the detail 
level, willingness of the project manager, etc... Applying such measures to these kinds of elementary models of the project systems cannot properly account for a measure of project complexity since they are in essence relative to the model. This is less the case with approaches based on systems thinking such as the one proposed by Haas.

However, for the last group of holistic complexity measures, such measures are sometimes difficult to calculate for non-skilled users, which make it all the more complex to perform and analyse them. Moreover, in the case of the Shannon number, the mathematical formulation does not permit a reference to real project complexity factors. Both the identification of important complexity sources and possible actions for complexity handling/reduction are not facilitated.

As a whole, in order to overcome the limits of existing measures, this paper aims at defining a systems thinking oriented index, which is as far as possible:

- Reliable, meaning the user can be confident with the measure.

- Intuitive and user-friendly, meaning it should be easily computed and implemented, and that users must understand why it assesses project complexity.

- Independent of the project models, so that the measure is an evaluation of project complexity and not an evaluation of the complexity of a given project model.

- Able to highlight project complexity sources when building up the measure, so that the user can analyse more properly project complexity and thus make his decisions with a better vision of the problem.

\section{Research methodology}

In order to do so, we propose to carry out the following methodology:

- Performing a broad state of the art to understand the multiple aspects of project complexity through the construction of a project complexity framework and refining it thanks to an international Delphi study (Part 4).

- Using the Analytic Hierarchy Process to build up the corresponding project complexity index (Part 5). 
- Testing the whole approach on a case study to draw conclusions and identify future research perspectives (Parts 6 and 7).

\section{Building up a project complexity framework using the}

\section{Delphi methodology}

\subsection{Identifying complexity factors using a systems-thinking approach}

This paper claims for the use of systems thinking to encompass all the aspects of projects. Basically, our systems thinking-based approach is notably based on or at least consistent with the works of (Boulding, 1956), (Von Bertalanffy, 1972), (Simon, 1981), (Le Moigne, 1990), (Penalva, 1997), (Williams, 2002), (Heylighen et al., 2006), (Bocquet et al., 2007). This paper considers the following definition of a system: "a system can be defined as an object, which, in a given environment, aims at reaching some objectives (teleological aspect) by doing an activity (functional aspect) while its internal structure (ontological aspect) evolves through time (genetic aspect) without losing its own identity" (Vidal and al., 2007). According to this definition, a project can be considered as a system. As a whole, a very large number of possible project complexity factors can be identified, when structuring a literature review using the four aspects of systems thinking (which permits that the identification of these factors is quite robust). This list was constituted, knowing that some factors were gathered under a common denomination in the end. The final list is composed of 70 project complexity factors.

\subsection{Structuring the framework}

It appeared that in order to make more sense both for academic and industrial practitioners, instead of using the 4 aspects of systems thinking to structure the framework, another typology was needed. That is why we used the following structure for the framework:

- First, there is a categorization into two columns, splitting factors using Baccarini's traditional dichotomy (technical / organizational) (Baccarini, 1999) 
- Then, there is a categorization into four rows, using four families of factors, the denomination of which was commonly used in fieldwork and in the literature (since these denominations have widely been used in research articles for instance): size, variety, interdependencies and context-dependence.

This framework aims at being a reference for any practitioner to identify and characterize some aspects of its project complexity, so that he can understand more efficiently the stakes of its project complexity management.

\subsection{Refining the framework using an international Delphi study}

With this framework, project complexity appears as a multiple aspects or multiple criteria characteristic of a project. Measuring it should thus require the consideration of these multiple aspects thanks to the proper use of a pertinent multi-criteria decision-making methodology now that the multiple aspects of project complexity have been identified. However, according to Baker and al. (Baker et al., 2001), criteria used in multi-criteria decision making methods should be:

- able to discriminate among the alternatives and to support the comparison of the performance of the alternatives

- complete to include all goals,

- operational and meaningful,

- non-redundant,

- few in number.

Here, the multiple aspects are not few in number and implementing it could quickly be impossible in fieldwork. That is why we called for a refining of this framework thanks to an international Delphi study which was carried out on academic and industrial practitioners. This Delphi study makes the point of ongoing publications in which detailed results of this study will be found. However, a few words can be said about it thanks to Figure 1, which draws a synthesis of our approach and results. The Delphi survey was conducted thanks to BCC electronic mail sent to 19 international academic and 19 industrial experts in project management, who were varied in terms of geographic location and gender. 
The Delphi survey group size appears to be very different in the literature. However, it is often recommended to have a group between 9 and 18 participants in order to draw some relevant conclusions and avoid at the same time difficulty to reach consensus among experts. We argue, such as in (Okoli and Pawlowski, 2004), that an experts categorization should be made properly before undertaking the Delphi survey in order to build up the most representative panel. As for them, Skulmoski et al. require different aspects for the participants to be selected in the Delphi survey panel (Skulmoski et al., 2007):

- Sufficient knowledge and experience about the survey issues,

- Capacity, willingness and time to participate,

- Good communication skills.

Our prospective panel was then constituted of 38 experts, 19 of them being industrial practitioners (identified notably thanks to professional or scholar social networks) and 19 being academics (identified notably thanks to their publications), and at the same time 19 being men, 19 being women. The questionnaire was introduced by a page explaining the overall purpose and structure of the survey as well as the experts anonymity conditions at each stage of the study. The questionnaire was divided into eight sections, following the structure of the project complexity framework. Participants were asked to evaluate the contribution of each factor to project complexity on 5-level Likert scales. We left them the possibility not to answer, to answer they did not know, or to add any other complexity factor which would have been missing.

\section{Figure 1. Overall process during the international Delphi study}

Of the first 18 proposed project complexity drivers after the panelists' evaluation (considered as essential), only 2 of them (11.1\%) are of a technological type (Figure 2). Organizational complexity thus seems to be the greatest source of complexity for projects and project management today. Project managers should thus focus on organizational issues when tackling and dealing with complexity. This also appears to be legitimate when discussing with industrials facing their project day-to-day life. Of these first 18 project complexity drivers, 11 of them belong to the family 
of project interdependencies (61.1\%), making it the most contributive family of project complexity drivers, before context-dependence $(16,7 \%)$, variety $(16,7 \%)$ and size $(5.6 \%)$. This also appears to be consistent with former works of the academic literature and with the industrials' feelings about complexity in discussions. This is also enlightened by the number of tools and works that have been developed to try to better catch project interactions and interdependencies, such as interactions model (Marle, 2002), or Design Structure Matrices (Steward, 1981).

Figure 2. Synthesis of Delphi results for each criterion, sorted by decreasing mean value

The 18 essential factors constitute the refined project complexity framework, which can be found hereunder in Figure 3.

Figure 3. Refined project complexity framework

This refined project complexity framework constitutes the basis of project complexity evaluation problem, which we propose to address thanks to the use of a proper multi-criteria decision methodology.

\section{Using the Analytic Hierarchy Process (AHP) to assess project complexity}

\subsection{Choosing the AHP}

In general, decision-making is the study of identifying and choosing alternatives based on the values and preferences of the decision-maker. Making a decision implies that some alternatives are to be considered and that one chooses the alternative(s) that possibly best fits with the goals, objectives, desires and values of the problem. Choosing the most suitable multi-criteria methodology is in itself a multi-criteria choice. 
From Gershon (1981), Deason (1984) and Tecle (1988), six criteria and 30 methods are identified for this problem. Indeed, regarding the issue of project complexity evaluation, preferences are given to intuitiveness, pertinence, notoriety and adequacy to the project management context. Moreover, the method should be able not only to rank the alternatives, but also to propose scorings in order to facilitate the transition to the calculation of a complexity index.

Simultaneously, the literature study enabled to assess each of the 30 considered methods according to the criteria. Finally, a single synthesis criteria method, the Analytic Hierarchy Process (AHP), obtains the best score. This can notably be understood since Al-Harbi (2001) showed that AHP has numerous applications in the project management field (Bea and Lloveras, 2007; Gourc, 2006). For instance, Ahmad and Laplante (2006) used the AHP to select the most appropriate software project management tool. The authors argue that "the AHP provides a flexible, systematic, and repeatable evaluation procedure that can easily be understood by the decision- maker in selecting the appropriate software project management tool". Finally, the reader should note that the AHP also has many applications in different contexts which all underline the user-friendliness and intuitiveness of the methodology (Lin and al., 2008; Gerdsri and Kocaoglu, 2007; Chiu and Chen, 2008).

\subsection{The Analytic Hierarchy Process (AHP)}

The Analytic Hierarchy Process (AHP) was developed by Thomas Saaty (Saaty, 1977), (Saaty, 1980), (Saaty, 1990). It is a multi-criteria decision-making method which permits the relative assessment and prioritization of alternatives. The AHP is based on the use of pair-wise comparisons, which lead to the elaboration of a ratio scale. The AHP uses a model of the decision problem as a hierarchy, consisting of an overall goal, a group of alternatives, and a group of criteria which link the alternatives to the goal.

With the refined project complexity framework, an AHP hierarchical structure can be built. The overall goal (objective) is the ranking of alternatives (projects or project scenarios or areas) according to their complexity level, meaning the AHP score which is obtained in the end catches and aggregates the importance of complexity factors on each alternative. First level criteria (intermediary goals) correspond to the four groups of project complexity factors (project size, 
project variety, project interdependencies and project context-dependence). Second level criteria then correspond to the factors of the refined framework. Moreover, if the structure remains stable, rejected criteria after the Delphi study or new criteria can be added, or existing criteria can be omitted to better cling to a specific context.

\subsection{Proposing a project complexity index}

Calculations are then performed thanks to this hierarchical structure (for more detail, see (Saaty, 1977) or (Saaty, 1980). A global score is obtained for each alternative, this score underlining the relative value of the goal (here complexity) within the set of alternatives studied. Given this score, a relative measure of project complexity is proposed. Let $\mathrm{S}(\mathrm{i})$ be the priority score of alternative $\mathrm{A}_{\mathrm{i}}$ obtained thanks to AHP calculations $(0 \leq \mathrm{S}(\mathrm{i}) \leq 1)$. We propose that the relative complexity of alternative $A_{i}$, given the specific context of the set of alternatives, can be expressed as the following ratio:

$$
C I_{i}=\frac{S(i)}{\max (S(i))} \rightarrow 0 \leq C I_{i} \leq 1
$$

A relative project complexity scale between 0 and 1 can be built thanks to this approach (this index permits to classify projects / project scenarios / project areas according to their global score regarding the main project complexity sources). Subscales can then be defined in the same manner to focus on specific aspects of project complexity and highlight how a project is complex regarding interdependencies or context for instance.

\section{Case study}

\subsection{Introduction}

The case study takes place within a start-up firm, the main activity of which is the production of stage musicals in France. Staging musicals or theatre plays are definitely projects, as underlined by Lehner (Lehner, 2009): it refers to all artistic, technical and organizational processes which permit to stage a musical. Project start corresponds to the idea and choice of the show to stage. 
Project end is generally considered as the first performance or the first week of performances (the activities which follow are often considered as the core day-to-day running activities of a theatre production firm). In the case studied, the firm has a portfolio of 7 projects of musicals to be staged in 2010-2012. The managers of the firm, who have both artistic and industrial backgrounds, recently launched their activity. They are assisted by several possible investors and partners. They wonder which show(s) they should produce first. In this case, the achievement of the first performance is considered as part of the project. Project 1 is the production of a French adaptation of a Broadway musical, whereas projects 2 to 7 are original creations. Projects 1, 2, 6 and 7 include some special effects (notably pyrotechnical ones for some of them). Projects 1 to 6 require detailed work on costume and set design (notably with advanced mechanical structures and machinery for some of them).

As for them and as for us, project complexity appears here as one of the criteria which should be considered before making a decision on this issue. Other criteria may notably be linked with the overall project performance regarding the values creation processes of the project (notably in terms of profit, image, etc...). A global project selection process may then be defined after this study in order to include all these factors in a multi-criteria approach to select the best project. We focus only on project complexity evaluation for the moment. Currently, in the context of this firm, the importance of project complexity as a factor for selection is all the more true than the lack of experience in start-up firms implies even greater difficulties to properly handle project complexity. As a consequence, a proper evaluation of relative project complexity appears to be really necessary.

\subsection{Results}

We carried out our research thanks to interviews of some possible future project team members (5 participants) following the AHP evaluation process, given our hierarchical structure. These people were asked to perform an a priori ranking of the projects in terms of complexity. This a priori ranking was necessary to highlight the possible differences between their initial perception and the results obtained. 


\section{Figure 4. Overall criteria and sub-criteria weights: project complexity factors comparison}

The methodology and measure proposed in this research work proved to be helpful in this case study. First, as shown in Figure 4, a first table was built to analyse the situation of the firm regarding project complexity. The relative weight of each sub-criterion can be evaluated, which gives information on where projects are likely to be more complex within the firm. Project managers should pay particular attention to the project complexity factors which get the best relative score (last column in Figure 4). On the contrary, some aspects of project complexity (low scores) may potentially be neglected at a first sight. This piece of information thus permits one to concentrate more efficiently on the principal factors of project complexity under a given firm and project environment.

In the end, final results are obtained and permit to realise a ranking of projects according to a complexity scale / index (from 0 to 1), as shown on Figure 5. It can be noted that two projects (P6 and P1) appear to be much more complex than the others, then Project 2 appears to be significantly more complex than the other ones.

\section{Figure 5. Relative project complexity index in the case study}

First, the existence of a numerical relative evaluation of project complexity within a project portfolio appears to be promising since it permits to know which projects are to be the most complex ones, but also how complex projects are. Moreover, this global ranking according to the relative project complexity index we propose is all the more interesting in this case study since the employees who were interviewed had made an a priori ranking which was different. In that a priori ranking, P3 was ranked second and P7 was ranked third, whereas P6 was only placed fourth. With this numerical assessment of complexity and this ranking given, discussions were held with the participants, and communication around the notion of complexity was facilitated.

They started to share their experience on complexity factors and realized that the difference with the a priori ranking they had done was mainly due to some communication and psychological barriers they had. For instance, P7 was a priori ranked by them third because the majority of them did not know where to find the skills and competence for the design of a specific special 
effect. Four of them had thus ranked this project as one of the most complex ones (two of them had even ranked it as the most complex). But when performing the pair-wise comparisons, the fifth employee, who had ranked a priori P7 as the less complex, said that he had already worked with such special effects and knew who could design them easily. The others changed their minds. Such example in our case study proves both the necessity to facilitate and promote communication in order to manage complex projects more efficiently and the benefits obtained with the project complexity refined framework and index we propose.

Finally, before performing sensitivity analyses (which make the point of ongoing publications), we claim for the use of specific numerical and graphical comparisons of projects which obtain close scores. For instance, in this case, project 6 obtains a global score of 0.308 when project 1 obtains a score of 0.292 , which makes in the end a small difference (around 5\%). In order to assist the decision-makers with their decisions, a closer look is to be done over the two projects. When realizing that the score of interdependencies (the main factor) is 0.185 for project 6 and 0.142 for project 1 (difference of around 25\%), the people who were interviewed in this case study definitely evaluated project 6 more complex that project 1. Indeed, when analysing closer why such a difference was obtained, the participants underlined notably a greater specifications interdependence and interdependence of information systems for project 6 . These specific interdependencies seemed all the more difficult to handle for the participants, which led them to the conclusion to reject project 6 at the time of this study. More precise comparisons can even be performed when descending to the level of sub-criteria and comparing projects on 0 to 1 relative subscales.

In the end, the team chose to launch project 1 , which appeared to be a comprise between different factors: complexity, expected returns (financial, image, experience,...), etc... This practical conclusion about this case study underlines the fact that the project complexity measure we propose can notably be in the end one of the criteria used in the project selection problem within a portfolio. As a whole, the measure permitted both to highlight some important complexity sources (which underlines how it is helpful to understand better project complexity) and to facilitate communication around these notions, which was not done or not properly done before. We thus 
hope that, more than a criteria in the problem of project selection, this measure is also a tool to promote discussions about complexity due to a better understanding and visualisation of it.

\section{Conclusions and perspectives}

As a whole, this paper elaborates an AHP-based methodology and measure to evaluate relative project complexity. The works proposed here answer the problem which was set after the literature review on existing (project) complexity measures. Indeed, as shown theoretically and validated with a first case study, the project complexity index proposed here permits to overcome to a great extent the limits of existing ones as it is:

- Reliable, since the final users are confident with the results, measures and scales which are proposed. During the case study, no numerical result was ever challenged by the participants of the case study. Moreover, no other complexity factor was suggested by the participants even though they had the opportunity do so. On the contrary, the results permitted to identify more precisely project complexity sources which were consciously or unconsciously felt without being clearly mentioned or stated.

- Intuitive and user-friendly. The users understand the construction of the measure and scales, and why they do measure project complexity or the level of complexity regarding a given criterion, sub-criteria, or set of (sub-)criteria. This results in the end in a facilitation of communication on project complexity and project complexity factors.

- Globally independent of the project models which are used for project management. Indeed, no reference to project management tools or models (Work Breakdown Structure, PERT networks, Gantt charts, risk lists, etc...) was ever made during the construction of the measure or during the case study. However, the refined project complexity framework is the basis of the measure. One should not forget that this framework is in essence a specific model, not of a project, but of what project complexity stands for. As a consequence, the measure which is 
proposed refers theoretically to this project complexity model. However, the final user is free to change some aspects (project complexity factors) in the AHP hierarchical structure proposed in this study.

- Able to highlight project complexity sources when building up the global complexity scale and the subscales (as one can understand where the global score of each alternative comes from).

However, some limitations do appear in this work and offer perspectives for future research on project complexity evaluation.

- First, the case study which was carried out offers interesting insights on our approach (both for the obtained results, which helped the decision-makers in the firm, and for processes which were followed to implement this approach). However, its context was somewhat quite specific due to the sector of this firm. In particular, there was a low project management maturity level in the firm, with very few project management processes formalised, which implied some difficulties or hesitations when performing some pair-wise comparisons. This led us to think of two improvements. The first one is theoretical and consists in the introduction of fuzzy numbers (fuzzy-AHP for instance). The second one is more practical and consists in performing another case study to test the robustness of our approach in other contexts. Indeed, we aim at conducting a case study in a firm which has more background in project management (for instance in a civil engineering or automotive firm).

- A second observation is that the Analytic Hierarchy Process has received some criticisms on the fact that rankings can vary when adding or subtracting an alternative to the set of alternatives on which the study is performed (Holder, 1990). We thus recommend the users to give specific attention to the step when the set of alternatives to be compared is selected. For instance, projects on which the final users have too few information or data may not be selected first as the quality of pair-wise comparisons may be considerably reduced. Finally, even with 
these recommendations, as for any decision-making process and tools, great caution should be taken, notably thanks to careful sensitivity analyses.

- Finally, future research is going to explore the possibility to extend this model to an ANP (Analytic Network Process) model in order to integrate the correlation between the different project complexity factors (as suggested when calculating some Spearman's rank correlation coefficient). Indeed, Taliscali and Eran (Taliscali and Ercan, 2006) say that their results suggest that "the ANP model represents reality as well as reliability better than the AHP model" due to the better integration of the interactions which exist between criteria. We think that in our case, exploring the possibility of using the ANP may be interesting since in essence, the criteria and sub-criteria of our structure are not independent. However, the number of required judgement elicitations is likely to increase and become tougher when dealing with the interrelation between criteria or subcriteria.

\section{Acknowledgements}

The authors would like to thank people of the start-up for their support to this work.

\section{References}

Ahmad N. and Laplante P.A. (2006) - Software Project Management Tools: Making a Practical Decision Using AHP - SEW 2006, pp.76-84

Akileswaran V., Hazen G.B. and Morin T.L. (1983) - Complexity of the project sequencing problem - Operations Research Vol. 31, No. 4, pp. 772-778

Al-Harbi K.M.A.S. (2001) - Application of the AHP in project management - International Journal of Project Management, Volume 19, Number 1, pp. 19-27(9)

Austin, S., Newton, A., Steele, J. and Waskett, P. (2002) - Modelling and managing project complexity - International Journal of Project Management, Volume 20, 191-198 
Baker, D., Bridges, D., Hunter, R., Johnson, G., Krupa, J., Murphy, J. and Sorenson, K. (2001) Guidebook to Decision-Making Methods - WSRC-IM-2002-00002, Department of Energy, USA.

Baccarini D. (1996) - The concept of project complexity, a review - International Journal of Project Management, Vol.14, Issue 4, pp.201-204

Bea J. and Lloveras J. (2007) - Multicriteria decision making applied to project outsourcing International Conference on Engineering Design, ICED-07, Paris, France.

Bocquet J-C., Patay E., Schindler A., Dudezert A. (2007) - How to build a design product and its end- product system? An original approach called SCOS' - International Conference on Engineering Design, ICED'07, Paris, France.

Boulding K. (1956) - General Systems Theory, the Skeleton of Science - Management Science, Vol.2, Issue 3, pp.197-208

Chiu Y.J. and Chen Y.W. (2007) - Using AHP in patent valuation. Mathematical and Computer Modelling, 46(7-8):1054 - 1062

Deason, J., 1984. A multi-objective decision support system for water project portfolio selection. In: Ph.D. Dissertation, University of Virginia.

Edmonds, B. (1999) - Syntactic measures of complexity - Thesis of the University of Manchester for the degree of doctor of philosophy in the faculty of arts.

Gerdsri, N. and Kocaoglu, D.F. (2007) - Applying the Analytic Hierarchy Process (AHP) to build a strategic framework for technology roadmapping - Mathematical and Computer Modelling, 46(78):1071 - 1080

Gershon, M., 1981. Model choice in multi-objective decision making in natural resource systems. In: Ph.D. Dissertation, University of Arizona.

Gourc, D. (2006) - Vers un modèle conceptuel du risque pour le pilotage et la conduite des activités de biens et de services. Propositions pour une conduite des projets et une gestion des risques intégrées. - Dossier d'habilitation à diriger des recherches présenté à l'institut national polytechnique de Toulouse.

Haas, K.B. (2009) - Managing complex projects: a new model - Vienna, VA : Management Concepts. 
Heylighen, F., Cilliers, P. and Gershenson, C. (2006) - Complexity and Philosophy - Complexity, Science and Society. Ed. Radcliffe.

Holder, R.D. (1990) - Some comments on the analytic hierarchy process - Journal of Operational Research Society 4111 (pp. 1073-1076

Kaimann, R.A. (1974) - Coefficient of Network Complexity - Management Science,Vol. 21, No. 2, pp. $172-177$

Latva-Koivisto A. (2001) - Finding a complexity measure for business process models - Research report Helsinki University of Technology, Systems Analysis Laboratory

Le Moigne, J.L. (1990) - La théorie du système général. Théorie de la modélisation - Presses Universitaires de France.

Lehner J.M. (2009) - The staging model: The contribution of classical theatre directors to project management in development contexts - International Journal of Project Management, Volume 27, Issue 3, Pages 195-205

Lin, C.C., Wang, W.C., and Yu, W.D. (2008) - Improving AHP for construction with an adaptive AHP approach - Automation in Construction, Vol. 17, p. 180 - 187.

Marle, F. (2002) - Modèle d’informations et méthodes pour aider à la prise de décision en management de projets - Thèse en Génie Industriel de l'Ecole Centrale Paris.

Morel, B. and Ramanujam, R. (1999) - Through the looking glass of complexity : the dynamics of organizations as adaptive and evolving systems - Organization science Vol.10, No.3, pp.278-293

Nassar, K. M. and Hegab, M. Y. (2006) - Developing a complexity measure for schedules - Journal of Construction Engineering and Management, 132 (6), 554-561.

Penalva, J.M. (1997) - La modélisation par les systèmes en situations complexes - Thèse en sciences de Parix XI Orsay préparée au Laboratoire d’Informatique appliquée de Commissariat à l'Energie Atomique.

Saaty, T. (1977) - A scaling method for priorities in hierarchical structures - Journal of Mathematical Psychology, 15, p. 234-281.

Saaty, T. (1980) - The Analytic Hierarchy Process: Planning, Priority Setting, ResourceAllocation - McGraw-Hill. 
Saaty, T.L. (1990) - How to make a decision: the analytic hierarchy process - European Journal of Operational Research, 48, 9-26.

Shannon, C.E. (1951) - The mathematical theory of communication - Bell Systems Technological Journal, No. 27, pp.379-423.

Simon, H.A., (1981) - The Sciences of the artificial - Cambridge The MIT Press.

Sinha, S., Thomson, A.I. and Kumar, B. (2001) - A complexity index for the design process International Conference on Engineering Design, ICED’01, Vol.1, Glasgow, pp.157-163, Professional Engineering Publishing, Bury St Edmunds.

Taslicali A.K. and Ercan S. (2006) - The analytic hierarchy \& the analytic network processes in multicriteria decision making: A comparative study - Journal of Aeronautics and Space Technologies, Volume 2, Number: 4, p. 55-65

Tecle, A., 1988. Choice of multicriteria decision making techniques for watershed management. In: Ph.D. Dissertation, The University of Arizona.

Temperley, H.M.V. (1981) - Graph Theory and Applications - England: Ellis Horwood Ltd.

Vidal, L.A., Marle, F. and Bocquet, J.C. (2007) - Modelling project complexity - International Conference on Engineering Design, ICED'07, Paris, France.

Vidal, L.A., Marle, F. and Bocquet, J.C. (2008) - Project complexity understanding and modelling to assist project management - PMI Research Conference, 2008. Warsow, Poland.

Whitty, S.J. and Maylor, H. (2009) - And then came Complex Project Management - International Journal of Project Management, Volume 27, Issue 3, Pages 304-310

Williams, T.M. (1999) - The need for new paradigms of project complexity - International Journal of Project Management, Volume 17, Issue 5, Pages 269-273

Williams, T.M. (2002) - Modelling complex projects - Wiley and Sons. 


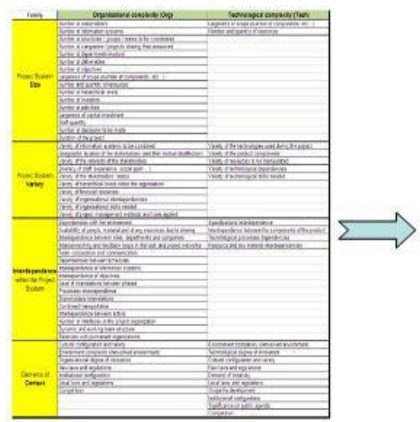

Initial project

complexity

framework
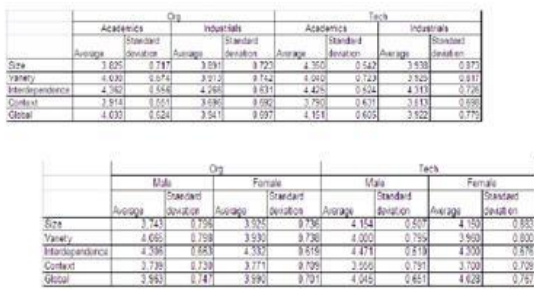

After consensus,

results and

conclusions

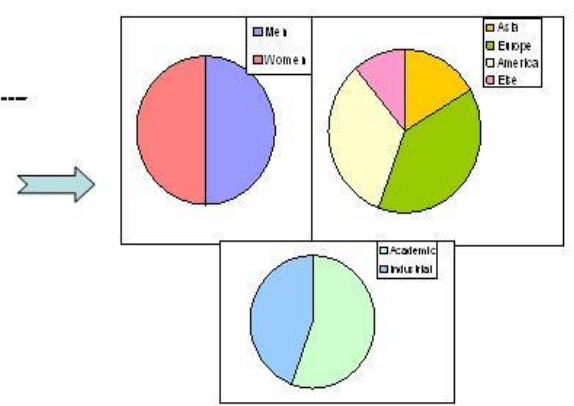

Identifying the participants (diverse academic and industrial experts)

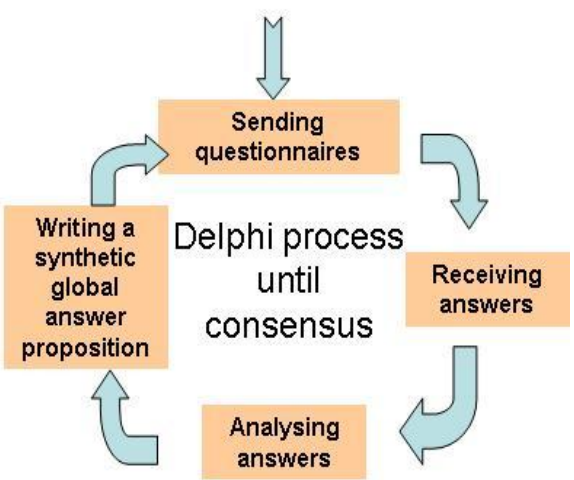

Figure 1. Overall process during the international Delphi study 
Criterion

|Family Compl. Type $\mid$ Average $\mid$ Std Dev

Dependencies with the environment

Cultural configuration and variety

Availability of people, material and of any resources due to sharing

Interdependence between sites, departments and companies

Environment complexity (networked environment)

Variety of information systems to be combined

Interconnectivity and feedback loops in the task and project networks

Specifications interdependence

Environment complexity (networked environment)

Team cooperation and communication

Number of stakeholders

Dependencies between schedules

Interdependence of information systems

Interdependence of objectives

Geographic location of the stakeholders (and their mutual disaffection

Variety of the interests of the stakeholders

Level of interrelations between phases

Processes interdependence

Number of information systems

Number of structures / groups / teams to be coordinated

Diversity of staff (experience social span ...)

Stakeholders interrelations

Interdependence between the components of the product

Technological processes dependencies

Number of companies / projects sharing their resources

Combined transportation

Largeness of scope (number of components. etc...)

Interdependence between actors

Technological degree of innovation

Variety of the technologies used during the project

Organisational degree of innovation

Number of departments involved

Variety of the product components

Cultural configuration and variety

Number of deliverables

Number of objectives

Variety of the stakeholders' status

\begin{tabular}{|c|c|c|c|}
\hline Int & Org & 4.889 & 0.323 \\
\hline Cont & Org & 4.833 & 0.514 \\
\hline
\end{tabular}

\begin{tabular}{|c|c|c|c|}
\hline Cont & Org & 4,833 & 0,514 \\
\hline Int & Org & 4.722 & 0.461 \\
\hline
\end{tabular}

.

Variety of resources to be manipulated

Number and quantity of resources

Number of interfaces in the project o

Number and quantity of resources

Variety of hierarchical levels within the organisation

Resource and raw material interdependencies

Variety of financial resources

Variety of technological dependencies

New laws and regulations

Number of hierarchical levels

Number of investors

New laws and regulations

Demand of creativity

Number of activities

Variety of organisational interdependencies

Variety of organisational skills needed

Largeness of capital investment

Variety of technological skills needed

Institutional configuration

Local laws and regulations

Scope for development

Local laws and regulations

Institutional configuration

Staff quantity

Dynamic and evolving team structure

Significance on public agenda

Number of decisions to be made

Relations with permanent organizations

Competition

Variety of project management methods and tools applied

Duration of the project

Competition

\begin{tabular}{|l|c|c|c|c|}
\hline organisation & Var & Org & 3.944 & 0.639 \\
\hline & Int & Tech & 3.944 & 0.725 \\
\hline & Var & Org & 3.869 & 0.758 \\
\hline & Var & Tech & 3.889 & 0.583 \\
\hline & Cont & Tech & 3.889 & 0.471 \\
\hline & Size & Org & 3.833 & 0.707 \\
\hline & Size & Org & 3.833 & 0.618 \\
\hline & Cont & Org & 3.833 & 0.618 \\
\hline & Cont & Tech & 3.778 & 0.808 \\
\hline & Size & Org & 3.722 & 0.752 \\
\hline & Var & Org & 3.556 & 0.922 \\
\hline & Var & Org & 3.556 & 0.856 \\
\hline & Size & Org & 3.500 & 0.786 \\
\hline & Var & Tech & 3.500 & 0.707 \\
\hline & Cont & Org & 3.444 & 0.616 \\
\hline & Cont & Tech & 3.444 & 0.511 \\
\hline & Cont & Tech & 3.444 & 0.511 \\
\hline & Cont & Org & 3.389 & 0.502 \\
\hline & Cont & Tech & 3.389 & 0.698 \\
\hline & Size & Org & 3.167 & 0.707 \\
\hline & Int & Org & 3.000 & 0.594 \\
\hline & Cont & Tech & 2.833 & 0.857 \\
\hline & Size & Org & 2.722 & 0.752 \\
\hline & Int & Org & 2.667 & 0.767 \\
\hline & Cont & Tech & 2.611 & 0.850 \\
\hline & Var & Org & 2.556 & 0.616 \\
\hline & Size & Org & 2.500 & 0.786 \\
\hline & Cont & Org & 2.278 & 0.826 \\
\hline & & & & \\
& & & & 3.936 \\
& & & &
\end{tabular}

Figure 2. Synthesis of Delphi results for each criterion, sorted by decreasing mean value 


\begin{tabular}{|c|c|c|}
\hline Family & Organisational Complexity (Org) & Technological Complexity (Tech) \\
\hline Project system size & Number of stakeholders & \\
\hline \multirow[t]{3}{*}{ Project system variety } & Variety of information systems to be combined & \\
\hline & Geographic location of the stakeholders (and their mutual disaffection) & \\
\hline & Variety of the interests of the stakeholders & \\
\hline \multirow[t]{10}{*}{ Project system interdependencies } & Dependencies with the environment & Specifications interdependence \\
\hline & Availability of people, material and of any resources due to sharing & \\
\hline & Interdependence between sites, departments and companies & \\
\hline & Interconnectivity and feedback loop in the task and project networks & \\
\hline & Team cooperation and communication & \\
\hline & Dependencies between schedules & \\
\hline & Interdependence of information systems & \\
\hline & Interdependence of objectives & \\
\hline & Level of interrelation between phases & \\
\hline & Processes interdependence & \\
\hline \multirow[t]{2}{*}{ Project system context-dependence } & Cultural configuration and variety & Environment complexity (networked environment) \\
\hline & Environment complexity (networked envrionment) & \\
\hline
\end{tabular}

Figure 3. Refined project complexity framework 


\begin{tabular}{|c|c|c|c|c|c|}
\hline Criteria (C) & C weights & Sub-criteria (SC) & SC weights & Total weights & Relative value \\
\hline C1 - Project Size & 0,142 & SC1-Number of stakeholders & 1,000 & 0,142 & 0,804 \\
\hline \multirow[t]{3}{*}{ C2 - Project variety } & \multirow[t]{3}{*}{0,151} & $\mathrm{SC2}$ - Variety of inform ations systems to be combined & 0,057 & 0,009 & 0,049 \\
\hline & & SC3-Geographic location of the stakeholders & 0,295 & 0,045 & 0,252 \\
\hline & & $\mathrm{SC} 4$-Variety of the interests of the stakeholders & 0,649 & 0,098 & 0,555 \\
\hline \multirow[t]{10}{*}{ C 3 -Project interdependencies } & \multirow[t]{10}{*}{0,556} & SC5-Dependencies with the environment & 0,092 & 0,051 & 0,290 \\
\hline & & SC6 - Availability of people, $m$ ate rial and... due to sharing & 0,042 & 0,024 & 0,133 \\
\hline & & SC7 - Interdependence between sites, departments and. & 0,062 & 0,034 & 0,194 \\
\hline & & SC8 - Interconnectivity/Feedback loops in the project networks & 0,020 & 0,011 & 0,062 \\
\hline & & Sc9-Team cooperation and com munication & 0,189 & 0,105 & 0,596 \\
\hline & & SC10-Dependencies between schedules & 0,042 & 0,024 & 0,133 \\
\hline & & SC11-Interdependence of inform ation systems & 0,019 & 0,011 & 0,060 \\
\hline & & SC12-Interdependence of objectives & 0,122 & 0,068 & 0,383 \\
\hline & & SC13-Level of interrelations between phases & 0,094 & 0,052 & 0,297 \\
\hline & & SC14-Specification Interdependence & 0,318 & 0,177 & 1,000 \\
\hline \multirow[t]{3}{*}{ C4-Project context-dependence } & \multirow[t]{3}{*}{0,151} & SC15-Cultural configuration and variety & 0,633 & 0,096 & 0,542 \\
\hline & & SC16-Environment organisational com plexity & 0,260 & 0,039 & 0,223 \\
\hline & & SC17-Environment technological complexity & 0,106 & 0,016 & 0,091 \\
\hline
\end{tabular}

Figure 4. Overall criteria and sub-criteria weights: project complexity factors comparison 


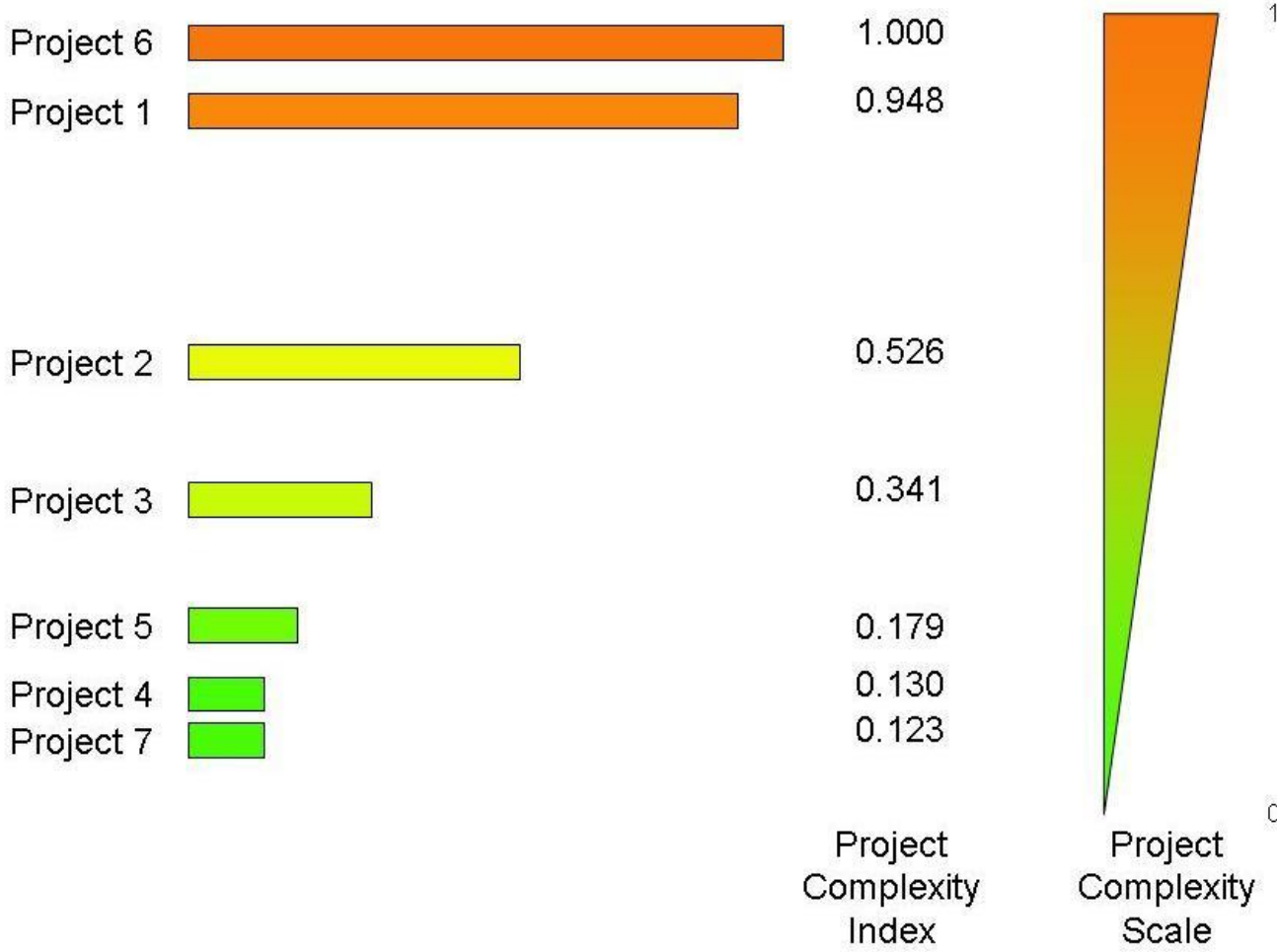

Figure 5. Relative project complexity index in the case study 